\title{
Framework of High-Technology Industry Innovation of China: Intellectual Property Protection and Industrial Knowledge Base
}

\author{
Weidong Wang1,2, Wei Song1, Linyu Fang ${ }^{3}$ \\ ${ }^{1}$ School of Public Affairs, University of Science and Technology of China, Hefei, China \\ ${ }^{2}$ School of Economic and Management, Shaoxing University, Shaoxing, China \\ ${ }^{3}$ Xiamen University Tan Kah Kee College, Xiamen, China \\ Email: songwei@ustc.edu.cn, 497261983@qq.com
}

Received 30 March 2015; accepted 22 May 2015; published 25 May 2015

Copyright (C) 2015 by authors and Scientific Research Publishing Inc.

This work is licensed under the Creative Commons Attribution International License (CC BY).

http://creativecommons.org/licenses/by/4.0/

\section{(c) (i) Open Access}

\begin{abstract}
Based on panel data from 2000 to 2012, quantitative analysis was conducted on the relationship between intellectual property protection and China's high-technology industry innovation. Results indicate that the intensity of intellectual property protection in China increases year by year and has a positive effect on the industrial knowledge base of the high-tech industry in China. The industrial knowledge base of each sub-industry in the high-tech industry of China has positive effects on owning inventive patents (OIP) and sales revenue of new products (SRNP). However, but stringent intellectual property protection has a certain inhibitory effect on OIP and SRNP for the manufacture of medicines, manufacture of medical equipment and measuring instruments, and manufacture of electronic and communication equipment. Moreover, stringent intellectual property protection has negative effects on OIP of all five sub-industries of the high-tech industry in China.
\end{abstract}

Keywords

Intellectual Property Protection, High-Tech Industry, Industrial Knowledge Base

\section{Introduction}

Innovation in high-technology industry requires an intellectual property system that has a guarantee. Since the promulgation of the patent law in 1982, the intellectual property system in China developed rapidly. China has successfully established the intellectual property management system and operation mechanism that are consistent with the international standards and the actual situation in China. Moreover, the agreement on Trade-related 
Aspects of Intellectual Property Right, which was promulgated by the World Trade Organization in 1994, intimately linked intellectual property rights (IPR) to economics and trade. The agreement also enhanced the global scope of intellectual property protection [1]. Intellectual property protection (IPP) is an important motivation that promotes the development of national science and technology innovation [2].

Given the important role of IPR in promoting technological change and economic growth, improving the intensity of IPP becomes imperative [3]. However, IPP is a "double-edged sword" for the technological innovation of China in an open economy. Although IPP would promote the independent innovation of the industry, imitating the advanced technology in other countries to serve as the innovation subjects of China is suppressed.

High-tech industry innovation and development in China is crucial for economic development. How should the relationship between intellectual property protection and high-tech industry innovation in China be correctly understood? How does IPP affect the industrial knowledge base for high-tech industry innovation? If these questions can be answered, then the intellectual property system in China could improve and enable the formulation of an effective high-tech industry policy.

\section{Literature Review}

\subsection{Intellectual Property Protection}

Determining the intensity of IPP is a prerequisite in studying the influence of IPP on others. Ferrantino [4] measured each protection index in the patent law by using dummy variables. Mansfield [5] and Sherwood [6] rated the intensity of IPP based on self-evaluation questionnaires administered to professional managers and patent lawyers. Using intellectual property legislation text, Ginarte and Park [7] refined the evaluation criteria of patent protection by classifying the indices of patent protection into coverage area of protection, including membership in the international treaty, loss of protection, law enforcement measures, and length of protection. Han and Li [8] modified the Ginarte-Park method and evaluated the level of IPP in China from 1984 to 2002. $\mathrm{Xu}$ and Chen [9] constructed the index system of the intensity of IPP based on the indices of the intensities of the legislation and law enforcement, such as judicial protection, administrative protection, economic development, social public awareness, and international supervision. Shen and Liu [10] analyzed the actual strength of IPP in China from the aspects of economic development, rule of law, and implementing law, and then proposed a modified approach to measure IPP 1995 to 2007. Hong and Wu [11] pointed out that the match between the present level of IPP and the reality in one industry (including development phase, technological level, market structure, and characteristic of innovation) should be evaluated using the comparative appraisal method, and then the basic model of the comparative appraisal method and process should be investigated.

\subsection{Intellectual Property Protection and Innovation}

IPP aims to encourage technology innovation and technology diffusion by protecting the interests of creators using appropriate policies. Whether IPP has an important role in promoting technological innovation, some studies concluded that enhancing IPP can effectively improve innovation output [12]. According to Maskus [1], the relationship between IPP and technological innovation is non-linear and technological innovation is not enhanced by improved IPP. Primo [13] suggested that a U-shaped nonlinear relationship exists between IPP and regional innovation capability. By using the panel data, Schneider [14] suggested that IPP has a positive effect on the domestic innovation in developed countries and might even negatively affect the innovation in developing countries. Chen and Puttitanun [15] concluded that innovation in a developing country increases with IPP, and the optimal IPP of a country depends on its economic development level (or technological ability) in a U-shaped way, first decreasing and then increasing. However, the relationship between IPP and innovation can be an inverted $U$ shape without considering the scale effect [16].

$\mathrm{He}$ and $\mathrm{Yu}$ [17] studied the relationship between IPP policy and technological innovation from the perspective of technical structure variables, and considered distinguishing the different structure of each industry, which includes the technological gap from developed countries and technological deviation within the industry, will become the basis for IPP policy making. The studies on the effects of IPP on the innovation of high-tech industries in China have some differences. One study found a strong relationship between innovation and IPP [18], and another found that IPP significantly promoted the technological innovation inputs and outputs of the high-tech industry in the country [19]. Gu and Zhai [20] indicated the inverse U-shaped relationship between IPP and in- 
novation rate, and observed that enhancing IPP increased the innovation rate when IPP was liberal. However, a further increase in stringent IPP can be harmful for the innovation rate. Dong and Sun [21] emphasized that the correlation between IPP and industrial innovation is unnecessary, depending on the level of industrial development and technology. Some studies also investigated the effect of IPP on the competitiveness of the high-tech industry in China [22] and on the import trade of high-tech products in China [23] [24].

\subsection{Regional Innovation, Industrial Knowledge Base, and Innovation}

Cooke [25] proposed the regional innovation system (RIS) and considered it as a system composed of enterprises, research institutions, educational institutions, and other private or public innovation subjects to support the innovation. Smith [26] first proposed the concept of distributed knowledge bases and explained the relationship between the knowledge base and innovation. The effects of firm knowledge base [27], industrial knowledge base [26], and economic knowledge base [28] on innovation have been explored. Research on regional innovation system has extended to the industry and knowledge levels. Industrial knowledge base is most closely associated with innovation at the industrial level, and different industrial developments and innovations require different knowledge bases [29]. However, compensating for the lack of basic research on the measurement of industry knowledge base is also necessary [30]. Wang, Song, and Song [31] pointed out the close connection between several metrics of industry knowledge base and innovation output in the high-tech industry.

In summary, prior studies discussed the concept or implication of IPP and innovation. They also developed the method to measure the levels of IPP and high-tech industry innovation, and conducted beneficial exploration to study the influence of IPP on high-tech industry innovation.

This paper studies the influence of IPP on high-tech industry innovation from the perspective of industry level, and an index system to estimate the level of IPP based on the theory of industrial knowledge base is developed. Then, quantification analysis of the relationship between IPP and high-tech industry innovation in China is conducted. The results showed that the intensity of IPP in China increased year by year, promoting the industry knowledge base of its high-tech industry innovation. Although stringent IPP had a restraining effect on owning invention patent (OIP) and sales revenue of new products (SRNP) of the high-tech industry in China, most of the indices of industrial knowledge base for the high-tech industry innovation increased and promoted the investment of expenditure on new product development, intramural expenditure on $\mathrm{R} \& \mathrm{D}$, and expenditure for assimilation of technology in the high-tech industry.

According to the classification of China Statistics Yearbook, the high-tech industry in China has five typical sub-industries, namely, manufacture of medicines (MM); manufacture of aircraft, spacecraft, and related equipment (MASRE); manufacture of electronic and communication equipment (MECE); manufacture of computers and office equipment (MCOE); and manufacture of medical equipment and measuring instruments (MMEMI). In general, the industrial knowledge base of all five high-tech sub-industries has a positive effect on OIP and SRNP. However, a significant difference exists between the sub-industries. Enhanced IPP has an inhibitory effect on OIP and SRNP for MM, MMEMI, and MECE. Moreover, enhanced IPP has a negative effect on all five sub-industries. By contrast, enhanced IPP stimulates SRNP for MCOE and MASRE. Therefore, further analyzing the reason why IPP has varying effects on the industrial knowledge base of each sub-industry is necessary.

\section{Model and Variable Design}

IPP affects both innovation input and output. The innovation input index is related to the process of technological development, whereas the innovation index is related to the process of transforming technological achievement. In general, technological innovation output has two aspects, namely, patent and non-patent. To gain a comprehensive understanding of the influence of the industrial knowledge base on high-tech industry innovation in China, this study measured the innovation from two aspects, namely, OIP and SRNP.

In general, $R \& D$ production function can be expressed as [32] [33]

$$
\mathrm{I}_{\mathrm{it}}=\mathrm{A}_{\mathrm{it}} \times \mathrm{SE}_{\mathrm{it}} \times \alpha_{1} \times \mathrm{SP}_{\mathrm{it}},
$$

where subscripts i and tenote industry and time period, respectively; I, SE, and SP represent the innovation output, R\&D capital, and human capital of domestic enterprises; and A represents other factors that may affect the innovation output. Innovation has two stages, and the corresponding innovation outputs are OIP and SRNP. According to the preceding and other related research [34], A can be further defined as 


$$
\mathrm{A}_{\mathrm{it}}=\lambda \mathrm{ef}(\mathrm{x})+\varepsilon_{\mathrm{it}} .
$$

where $\mathrm{f}(\mathrm{x})=\alpha_{1} \ln$ IPP it.

In this study, R\&D expenditure (SE) includes two aspects of absolute input (intramural expenditure on R\&D) and relative input (expenditure on new product development and expenditure for acquisition of foreign technology). Considering the convenience of data acquisition, this study introduced six indices of industry knowledge base, such as expenditure on new product development, and then applied the following models:

$$
\begin{aligned}
\operatorname{lnOIP}_{\mathrm{it}}= & \alpha_{0}+\alpha_{1} \ln (\mathrm{IPP})_{\mathrm{it}}+\alpha_{2} \ln (\mathrm{ENDP})_{\mathrm{it}}+\alpha_{3} \ln (\mathrm{RDPF})_{\mathrm{it}}+\alpha_{4} \ln (\mathrm{ERDI})_{\mathrm{it}}+\alpha_{5} \ln (\mathrm{CRDN})_{\mathrm{it}} \\
& +\alpha_{6} \ln (\mathrm{DAF})_{\mathrm{it}}+\alpha_{7} \ln (\mathrm{ITF})_{\mathrm{it}} \\
\operatorname{lnSRNP}_{\mathrm{it}}= & \alpha_{0}+\alpha_{1} \ln (\mathrm{IPP})_{\mathrm{it}}+\alpha_{2} \ln (\mathrm{ENDP})_{\mathrm{it}}+\alpha_{3} \ln (\mathrm{RDPF})_{\mathrm{it}}+\alpha_{4} \ln (\mathrm{ERDI})_{\mathrm{it}}+\alpha_{5} \ln (\mathrm{CRDN})_{\mathrm{it}} \\
& +\alpha_{6} \ln (\mathrm{DAF})_{\mathrm{it}}+\alpha_{7} \ln (\mathrm{ITF})_{\mathrm{it}}
\end{aligned}
$$

Generally, the ratio of scientists and engineers (RSE) was used to measure the level of human capital on enterprise innovation investment. Considering the convenience of data acquisition, this study used full-time equivalent of R\&D personnel (RDPF) instead of RSE to measure the human capital investment within the regional high-tech industry. CRDN is the number of R\&D institutions in companies, and they are the innovation subjects in RIS to improve the independent innovation ability, develop cooperation, and provide technical support to upgrade the enterprise products and large-scale production. ERDI represents intramural expenditure on $R \& D$, and measures the size of the material capital investment on industry knowledge creation. ENDP represents the expenditure on new product development because it is the key content of firm R\&D, as well as one of the strategies that determine the development and survival of enterprises. The size of ENDP of the overall high-tech industry reflects the input and capability the entire industry in new product development. The size of the expenditure for assimilation of technology (DAF) and expenditure for acquisition of foreign technology (ITF) reflect the ability to learn and absorb the industry knowledge base.

Most current empirical studies on IPP adopted Rapp, Rozek_2, and G-P methods to measure the level of IPP. Given that different countries have different judicial systems, which would affect the law enforcement level of IPP, the IPP level calculated using the aforementioned methods may not be consistent with the actual IPP level. To accurately measure the IPP level of China in the transformation period, Han and Li (2005) proposed a modified method based on the G-P method. However, Shen and Yao (2010) modified the method of Han and Li (2005) by introducing three indices at the level of economic development, rule of law, and law enforcement of intellectual property, and then measured the actual intensity of IPP in China from 1995 to 2007. This study adopted the method of Shen and Yao (2010) to measure the actual intensity of IPP in China from 2008 to 2012. The results showed that the intensity of IPP in China increased year by year.

This study adopted the panel data because of the brevity of the official statistical data on the high-tech industry of China and to ensure the quality of the samples given that this method could increase the amount of data estimation and degree of freedom while the multi-colinearity of the explanatory variables is reduced. We collected the data from China Statistical Yearbook on Science and Technology, China Statistics Yearbook on High Technology Industry, and China Statistical Yearbook, and used EVIEWS6.0 software to analyze them.

\section{Empirical Analysis}

\subsection{Stationary Test, Fixed Effect Model Test, and Random Effect Model Test}

This paper adopted Dickey-Fuller's ADF method to conduct a stationary test on the data series. After the stationary test on the indices of LNOIP, INSRNP, LNIPR2, LNENDP, and their first-order differences, the time series of LNOIP, INSRNP, LNIPR2, and LNENDP were non-stationary because their ADF values were all larger than the critical value of 1 . However, the ADF values of their first-order differences were lower than the critical value of 1 . Thus, the hypothesis was accepted and all were integrated to 1 . In general, fixed effect and random effect models were mainly considered to conduct panel data analysis. We used Hausman test to determine whether the model is a fixed effect model or a random effect model, and the result indicated that it was the former. Following the five sub-industry models, adjusted R-squared and F-statistics values were supported, and all model variables explained the dependent variable. 


\subsection{Results and Analysis}

\subsubsection{Results of Industry Analysis}

Table 1 shows a reverse relationship between IPP and OIP because their coefficient of elasticity was negative (the value was -1.639977) from 2000 to 2012. However, the intensity of IPP in China increased year by year; indicating that enhanced IPP has a certain inhibitory effect on OIP in the high-tech industry. However, all coefficients of elasticity between each index of industrial knowledge base and IPP were positive except for CRDN, indicating that an enhanced IPP has a positive effect on the industrial knowledge base in the high-tech industry of China, particularly for the indices of ERDI and ENDP from the perspective of OIP.

The coefficient of elasticity between IPP and SRNP was also negative from 2000 to 2012, indicating that enhanced IPP has a certain inhibitory effect on SRNP of the high-tech industry in China during the same period. Meanwhile, RDPF, CRDN, and ITF also had an inhibitory effect on SRNP because their coefficients of elasticity were all negative. However, the other three indices of industrial knowledge base, namely, ENDP, ERDI, and DAF, had positive effects on SRNP because their coefficients of elasticity were all positive. The results indicated that, from the SRNP perspective, an enhanced IPP not only had stimulative but also inhibitory effects on the industrial knowledge base of the innovation in the high-tech industry in China.

From the perspective of the single index of industrial knowledge base, an enhanced IPP would promote ENDP, ERDI, and DAF of the high-tech industry in China, but had an obvious inhibitory effect on CRDN. Enhanced IPP also had a different effect on ITF and RDPF. The result revealed that the improvement in the industrial knowledge base of the innovation in the high-tech industry of China mainly depended on the input of all aspects of funds, with a slight change on the enhancement of aspects of CRDN, ITF, and RDFF.

\subsubsection{Results of Sub-Industry Analysis}

Table 2 shows that enhanced IPP has a certain inhibitory effect on OIP and SRNP of MM, MMEMI, and MECE because all their coefficients of elasticity were negative. A certain difference was observed among these three sub-industries from the perspective of each index of industrial knowledge base. For MM, the coefficients of elasticity of RDFF and CRDN were negative, indicating that enhanced IPP had a considerably negative effect on MM. However, the coefficients of elasticity of ENDP and ITF were positive, indicating that an enhanced IPP improved the input of knowledge base of MM. Simultaneously, the coefficients of elasticity of expenditure for ITF and ERDI were also positive from the SRNP perspective.

For MECE, the coefficients of elasticity between IPP and all indices of industrial knowledge base (except for ENDP and ITF) were positive, indicating that enhanced IPP promoted the industrial knowledge base for the innovation of MECE. In other words, enhanced IPP had a positive effect on the industrial knowledge base for the innovation of MECE.

For MMEMI, the coefficients of elasticity between IPP and all indices of industrial knowledge base (except

Table 1. Relationship among OIP, SRNP, and industrial knowledge base of the high-tech industry.

\begin{tabular}{cccccc}
\hline Dependent variable & \multicolumn{2}{c}{ LNOIP } & \multicolumn{2}{c}{ LNSRNP } \\
\hline Variable & Coefficient & t-statistic & Coefficient & t-statistic \\
\hline LNIPR & -1.639977 & -1.452955 & -0.726608 & -1.831429 \\
LNENDP & 0.290758 & 0.396687 & 0.454869 & 1.765541 \\
LNRDPF & 0.307398 & 0.388767 & -0.455254 & -1.638013 \\
LNERDI & 1.490222 & 1.919882 & 0.943615 & 3.458546 \\
LNCRDN & -0.070365 & -0.244747 & -0.153275 & -1.516724 \\
LNDAF & 0.020308 & 0.052284 & 0.149423 & 1.094444 \\
LNITF & 0.036694 & & 0.179483 & -0.03183 & -0.442937 \\
C & -19.99737 & & -3.13873 & 2.749924 & 1.227939 \\
Adjusted R-squared & & 0.98618 & & & 0.993257 \\
F-statistic & & 123.3293 & & & 253.5035 \\
\hline
\end{tabular}


RDFF) were posited from the SRNP perspective, and the coefficients of elasticity between PP and all indices of industrial knowledge base (except ENDP and ITF) were positive from the OIP perspective. The result indicated that enhanced IPP had a positive effect on the industrial knowledge base for the innovation in MMEMI.

For MASRE and MCOE, enhanced IPP had a certain inhibitory effect on OIP, but considerably stimulated SRNP. From the perspective of each index of the industrial knowledge base, the coefficients of elasticity of ENDP for MASRE were positive, indicating that IPP improved ENDP in MASRE. The coefficients of elasticity of other indices were both positive and negative, but from an overall perspective, enhanced IPP had a positive effect on the industrial knowledge base for the technical innovation of MASRE. For MCOE, the coefficients of elasticity of most of the indices related to the industrial knowledge base, such as ENDP, were positive, indicating that enhanced IPP improved the industrial knowledge base for the technical innovation of MCOE. In other words, enhanced IPP had a positive effect on the industrial knowledge base for the technical innovation of MCOE.

In summary, enhanced IPP had different effects on different sub-industries. For MASRE and MCOE, IPP had a role in promoting SRNP, as well as a positive effect on each index of the industrial knowledge base (shows by Table 3). Although IPP has a certain inhibitory effect on SRNP for MMEMI and MECE, enhanced IPP

Table 2. Relationship between OIP and industrial knowledge base for each sub-industry in the high-tech industry of China.

\begin{tabular}{|c|c|c|c|c|c|c|c|c|c|c|}
\hline Variable & Coefficient & t-statistic & Coefficient & t-statistic & Coefficient & t-statistic & Coefficient & t-statistic & Coefficient & t-statistic \\
\hline LNIPR & -0.436668 & -0.531385 & -1.402959 & -1.012146 & -0.596016 & -0.488667 & -5.469836 & -2.110678 & -5.469836 & -0.488667 \\
\hline LNENDP & 2.425418 & 1.651028 & 0.451385 & 0.455703 & -1.304739 & -1.955068 & 4.346661 & 2.129666 & 4.346661 & -1.955068 \\
\hline LNRDPF & -0.757711 & -1.160224 & 0.554234 & 0.700987 & 2.132319 & 2.301485 & 0.165736 & 0.206103 & 0.165736 & 2.301485 \\
\hline LNERDI & -0.309055 & -0.285986 & 0.780284 & 0.737328 & 1.378107 & 1.894607 & -2.021787 & -1.708908 & -2.021787 & 1.894607 \\
\hline LNCRDN & -0.119987 & -0.318852 & -0.101296 & -0.068590 & 0.277573 & 0.795790 & 0.411778 & 0.800362 & 0.411778 & 0.795790 \\
\hline LNDAF & 0.150194 & 0.468372 & -0.253116 & -0.697919 & -0.414867 & -1.173188 & 0.107653 & 0.393186 & 0.107653 & -1.173188 \\
\hline LNITF & -0.467863 & -0.794236 & 0.042432 & 0.236226 & 0.218117 & 1.328461 & 0.085024 & 0.571982 & 0.085024 & 1.328461 \\
\hline $\mathrm{C}$ & -8.199777 & -3.008241 & -11.48383 & -1.393315 & -15.08642 & -2.539917 & -23.90648 & -2.753639 & -23.90648 & -2.539917 \\
\hline $\begin{array}{c}\text { Adjusted } \\
\text { R-squared }\end{array}$ & \multicolumn{2}{|c|}{0.984115} & \multicolumn{2}{|c|}{0.889620} & \multicolumn{2}{|c|}{0.984968} & \multicolumn{2}{|c|}{0.948320} & \multicolumn{2}{|c|}{0.959855} \\
\hline F-statistic & \multicolumn{2}{|c|}{107.2060} & \multicolumn{2}{|c|}{14.81648} & \multicolumn{2}{|c|}{113.3283} & \multicolumn{2}{|c|}{32.45678} & \multicolumn{2}{|c|}{32.45678} \\
\hline
\end{tabular}

Table 3. Relationship between SRNP and industrial knowledge base for each sub-industry in the high-tech industry in China.

\begin{tabular}{|c|c|c|c|c|c|c|c|c|c|c|}
\hline Variable & Coefficient & t-statistic & Coefficient & t-statistic & Coefficient & t-statistic & Coefficient & t-statistic & Coefficient & t-statistic \\
\hline LNIPR & -0.663490 & -1.518931 & 1.326115 & 1.895149 & -0.727092 & -1.071142 & 0.625243 & 0.447652 & -0.394386 & -0.701595 \\
\hline LNENDP & 0.131091 & 0.167875 & 1.408985 & 2.817763 & -0.152430 & -0.410404 & 0.161492 & 0.146809 & 0.002419 & 0.007627 \\
\hline LNRDPF & -0.282060 & -0.812502 & -0.096032 & -0.240601 & 0.274288 & 0.531944 & 0.136270 & 0.314421 & -0.129045 & -0.235786 \\
\hline LNERDI & 1.124981 & 1.958385 & -0.818261 & -1.531665 & 0.790500 & 1.952724 & 0.468967 & 0.735476 & 0.937215 & 2.165197 \\
\hline LNCRDN & -0.119613 & -0.597967 & 0.478971 & 0.642451 & 0.099690 & 0.513540 & -0.102371 & -0.369184 & 0.022252 & 0.092684 \\
\hline LNDAF & 0.207147 & 1.215236 & 0.172818 & 0.943924 & 0.255867 & 1.300095 & -0.145996 & -0.989360 & 0.029374 & 0.539623 \\
\hline LNITF & 0.136873 & 0.437113 & -0.228792 & -2.523141 & 0.009816 & 0.107420 & 0.142726 & 1.781508 & 0.072296 & 0.831573 \\
\hline $\mathrm{C}$ & -0.078832 & -0.054407 & 4.423892 & 1.063239 & 1.722970 & 0.521211 & 7.297804 & 1.559649 & 3.919196 & 2.477139 \\
\hline $\begin{array}{c}\text { Adjusted } \\
\text { R-squared }\end{array}$ & \multicolumn{2}{|c|}{0.991511} & \multicolumn{2}{|c|}{0.926592} & \multicolumn{2}{|c|}{0.974955} & \multicolumn{2}{|c|}{0.926623} & \multicolumn{2}{|c|}{0.992191} \\
\hline F-statistic & \multicolumn{2}{|c|}{201.2204} & \multicolumn{2}{|c|}{22.63846} & \multicolumn{2}{|c|}{67.73264} & \multicolumn{2}{|c|}{22.64857} & \multicolumn{2}{|c|}{218.816} \\
\hline
\end{tabular}


improved most of the index of the industrial knowledge base for industry innovation. However, IPP has relatively slight promotion for MM.

\section{Conclusions and Suggestions}

As IPP in China increased year by year, most of the indices of the industrial knowledge base for high-tech industry innovation were promoted. Enhanced IPP boosted the growth in ENDP, ERDI, and DAF in the high-tech industry, although it restrained the growth of OIP and SRNP.

The industrial knowledge base has a positive effect on OIP and SRNP in each sub-industry of the high-tech industry because most of their coefficients of elasticity were positive. Therefore, an enhanced IPP would improve the level of industrial knowledge base and be propitious to the high-tech industry innovation.

From the perspective of sub-industry, enhanced IPP has a certain inhibitory effect on OIP and SRNP for MM, MMEMI, and MECE, but stimulated SRNP for MCOE and MASRE. However, enhanced IPP has a negative effect on OIP for all five sub-industries. Further analyzing the reason why IPP has a different effect on the industrial knowledge base of each sub-industry is necessary.

Therefore, protecting IPR should be consistent with the characteristics and current situation of the development of the high-tech industry in China. The direction for IPP strategy should have a clear focus that considers the characteristics and current situation of the high-tech industry in China. To improve the ability for independent innovation in the high-tech industry, R\&D talents, as well as intellectual property talents should be enhanced and cultivated. More R\&D institutions within enterprises should be developed to guide the enterprises to innovate. Finally, the investment in DAF or cross-border acquisitions should be increased.

\section{Acknowledgements}

This work was supported by the Soft Science Research Plan Project of Zhejiang Province of China under Grant Nos. 2013C35066, the Soft Science Research Project of Anhui province of China under Grant Nos. 1402052002. All errors are ours.

\section{References}

[1] Maskus, K.E. (2001) Intellectual Property Challenges for Developing Countries: An Economic Perspective. University of Illinois Law Review, 1, 457-473.

[2] Kanwar, S. and Evenson, R. (2003) Does Intellectual Property Protection Spur Technological Change? Oxford Economic Papers-New Series, 55, 235-264. http://dx.doi.org/10.1093/oep/55.2.235

[3] Mondal, D. and Gupta, M.R. (2006) Innovation, Imitation and Intellectual Property Rights: A Note on Helpman's Model. Journal of Economics, 87, 29-53. http://dx.doi.org/10.1007/s00712-005-0154-6

[4] Ferrantino, M.J. (1993) The Effect of Intellectual Property Rights on International Trade and Investment. Weltwirtschaftliches Archiv, 129, 300-331. http://dx.doi.org/10.1007/BF02707699

[5] Mansfield, E. (1995) Intellectual Property Protection, Direct Investment, and Technology Transfer: Germany, Japan, and the United States (Vol. 27). World Bank Publications.

[6] Sherwood, R.M. (1996) Intellectual Property Systems and Investment Stimulation: The Rating of Systems in Eighteen Developing Countries. Idea, 37, 261.

[7] Ginarte, J.C. and Park, W.G. (1997) Determinants of Patent Rights: A Cross-National Study. Research Policy, 26, 283301. http://dx.doi.org/10.1016/S0048-7333(97)00022-X

[8] Han, Y.-X. and Li, H.-Z. (2005) Quantitative Analysis for Intellectual Property Protection Level of China. Studies in Science of Science, 23, 377-382.

[9] Xu, C.-M. and Chen, M. (2008) Determination and Verification of Intensity of China's Intellectual Property Protection. Intellectual Property, 18, 27-36.

[10] Shen, G. and Liu, J. (2009) Nominal Level and Actual Strength of China's Intellectual Property Protection (IPP) under the TRIPS Agreement. Finance \& Trade Economics, 11, 66-71.

[11] Hong, Y. and Wu, Y. (2011) Research on the Comparative Appraisal Method of Intellectual Property Right Protection in Developing Countries-From the Perspective of Influencing Factors of Intellectual Property Right Protection. Science of Science and Management of S. \& T., 32, 36-42.

[12] Denicolo, V. (1996) Patent Races and Optimal Patent Breadth and Length. The Journal of Industrial Economics, 44, 249-265. http://dx.doi.org/10.2307/2950496 
[13] Primo, B. (2000) Intellectual Property Rights and Economic Development. World Bank Discussion Papers, 4121.

[14] Schneider, P.H. (2005) International Trade, Economic Growth and Intellectual Property Rights: A Panel Data Study of Developed and Developing Countries. Journal of Development Economics, 78, 529-547. http://dx.doi.org/10.1016/j.jdeveco.2004.09.001

[15] Chen, Y.M. and Puttitanun, T. (2005) Intellectual Property Rights and Innovation in Developing Countries. Journal of Development Economics, 78, 474-493. http://dx.doi.org/10.1016/j.jdeveco.2004.11.005

[16] Furukawa, Y. (2010) Intellectual Property Protection and Innovation: An Inverted-U Relationship. Economics Letters, 109, 99-101. http://dx.doi.org/10.1016/j.econlet.2010.09.004

[17] He, G. and Yu, Y. (2011) Intellectual Property Right Protection and Technological Innovation: A Theoretical Analysis. Science Research Management, 32, 148-156.

[18] Zhao, Y., Zhou, J. and Xu, Z. (2008) High-Tech Enterprises and Its Implications. Science of Science and Management of S. \& T., 58-63.

[19] Li, R. and Gong, S.-E. (2013) Intellectual Property Right Protection and China's Technology Innovation in Opening Circumstance-Based on the Provincial Data from 1997 to 2010. R\&D Management, 25, 1-9.

[20] Gu, Q. and Zhai, S.-P. (2013) Intellectual Property Protection, Financial Development and Innovation Efficiency of High Technology Industry_Analysis Based on Provincial Panel Data. Soft Science, 27, 42-46.

[21] Dong, Y. and Sun, H. (2012) Quantitative Analysis of Effect of Intellectual Property Protection on Industrial Innovation: Take the High Technology Industry for Example. World Economy Study, 11-15.

[22] Zheng, Y.-L. and Song, H. (2012) An Empirical Research on the Impact of China's Intellectual Property Protection on Competitiveness of Chinese High-Tech Industry. China Soft Science, 147-155.

[23] Qi, J.-Y. and Xu, H.-L. (2011) The Import Trade Effect of Intellectual Property Rights Policy: Expansion or Monopoly? Empirical Study on Import Trade of High-Tech Products in China. Journal of Finance and Economics, 37, 68-78.

[24] Shen, G. and Yao, B. (2010) Intellectual Property Protection and Foreign Trade Development in China: The Case of High-Tech Product Import Trade. Nankai Economic Studies, 135-152.

[25] Cooke, P. (1992) Regional Innovation Systems: Competitive Regulation in the New Europe. Geoforum, 23, 365-382. http://dx.doi.org/10.1016/0016-7185(92)90048-9

[26] Smith, K. (2000) What Is the "Knowledge Economy”? Knowledge-Intensive Industries and Distributed Knowledge Bases: AEGIS. University of Western Sydney, Sydney.

[27] Saviotti, P.P. (2007) On the Dynamics of Generation and Utilisation of Knowledge: The Local Character of Knowledge. Structural Change and Economic Dynamics, 18, 387-408. http://dx.doi.org/10.1016/j.strueco.2007.03.003

[28] Branstetter, L.G., Fisman, R. and Foley, C.F. (2006) Do Stronger Intellectual Property Rights Increase International Technology Transfer? Empirical Evidence from US Firm-Level Panel Data. Quarterly Journal of Economics, 121, 321-349. http://dx.doi.org/10.1093/qje/121.1.321

[29] Xue, J. and Zhang, Z. (2011) Research of Regional Innovation Based on Knowledge Base, Innovation Network and Interactive Learning. Forum on Science and Technology in China, 104-111.

[30] Niu, P.-Q., Xie, F.-J. and Li, B.-Q. (2011) A Theoretic Research on the Effect of Industrial Knowledge Base on the Building of RIS. R\&D Management, 23, 101-109.

[31] Wang, W., Song, W. and Song, X. (2014) Research on Relations between Industry Knowledge Base and Enterprise Innovation-Based on Canonical Correlation Analysis on High Technology Industry. Science and Technology Management Research.

[32] Jefferson, G.H., Bai, H.M., Guan, X.J. and Yu, X.Y. (2006) R\&D Performance in Chinese Industry. Economics of Innovation and New Technology, 15, 345-366. http://dx.doi.org/10.1080/10438590500512851

[33] Koeller, C.T. (1995) Innovation, Market Structure and Firm Size: A Simultaneous Equations Model. Managerial and Decision Economics, 16, 259-269. http://dx.doi.org/10.1002/mde.4090160308

[34] Hu, A.G.Z., Jefferson, G.H. and Qian, J.C. (2005) R\&D and Technology Transfer: Firm-Level Evidence from Chinese Industry. Review of Economics and Statistics, 87, 780-786. http://dx.doi.org/10.1162/003465305775098143 